\title{
Integrating a learning outcomes assessment rubric into a deteriorating patient simulation for undergraduate nursing students
}

\author{
Marian Luctkar-Flude*1, Deborah Tregunno', Rylan Egan ${ }^{1}$, Kim Sears $^{1}$, Jane Tyerman ${ }^{2}$ \\ ${ }^{1}$ School of Nursing, Queen's University, Canada \\ ${ }^{2}$ School of Nursing, Trent University, Canada
}

Received: February 27, 2019

Accepted: April 23, 2019

Online Published: April 29, 2019

DOI: 10.5430/jnep.v9n8p65

URL: https://doi.org/10.5430/jnep.v9n8p65

\begin{abstract}
Background: Few studies have examined effective methods to prepare learners to participate in simulation-based learning experiences. Similarly, there is limited literature on valid, reliable assessment methods to determine whether clinical simulation learning outcomes have been met. We developed a learning outcomes assessment rubric to support self-regulated learning and assessment during presimulation preparation and debriefing.

Methods: Fourth-year undergraduate nursing students enrolled in a critical care nursing course participated in two deteriorating patient simulations, one delivered in a traditional format, and the other using a new format incorporating a learning outcomes assessment rubric into presimulation preparation and debriefing. A descriptive survey evaluated learner perceived competence with deteriorating patients and satisfaction with the two simulations formats. Learner self-assessment data using the rubric was collected pre and post simulation.

Results: Learner satisfaction with the deteriorating patient scenario and accompanying assessment rubric was very high. Learners were significantly more satisfied with the simulation scenario delivered using the new format which included the assessment rubric than with the standard format without the assessment rubric $(p<.001)$. Learners valued the opportunity to identify their own learning needs, and reported increased competence in management of a deteriorating patient following the simulation $(p<$ $.001)$.

Conclusions: Senior nursing students perceived that integration of learning outcomes assessment rubrics into simulation design enhanced their self-regulated learning and presimulation preparation. Further research is needed to explore presimulation preparation strategies and to validate rubrics used for summative assessment.
\end{abstract}

Key Words: Clinical simulation, Nursing education, Learning outcomes, Assessment rubrics, Presimulation preparation, Self-regulated learning

\section{INTRODUCTION}

\subsection{Introduction of the issues}

Newly graduated nurses are expected to be able to recognize and appropriately respond to subtle changes in patient status that reflect patient deterioration. Clinical simulation is an educational strategy that is used to expose learners to deteriorating patient situations; however learners who are unprepared may not perform well or experience increased anxiety, and it may be unclear whether or not the desired learning outcomes have been achieved. In keeping with

*Correspondence: Marian Luctkar-Flude; Email: mfl1@queensu.ca; Address: School of Nursing, Queen’s University, Canada. 
principles of self-regulated learning we proposed the use of learning outcomes assessment rubrics as a strategy to enhance presimulation preparation and self-reflection during debriefing for learners, as well as to provide facilitators with an explicit guide to providing formative feedback following simulation-based learning experiences which helps learners identify their strengths and weaknesses.

\subsection{Management of deteriorating patients}

Delayed recognition of and intervention for a deteriorating patient is associated with an increased risk for adverse outcomes. ${ }^{[1]}$ Novice nurses have been found to have insufficient knowledge on and exposure to deteriorating patient situations, and are thus more anxious and uncertain caring for unstable patients and unable to effectively recognize subtle changes in clinical signs. ${ }^{[2,3]}$ Research suggests that final year undergraduate nursing students lack the knowledge, clinical skills, team work and situational awareness necessary for managing deteriorating patients. ${ }^{[4]}$ With numbers of patients with complex health problems increasing, newly graduated nurses are caring for sicker patients. ${ }^{[5]}$ Thus, nursing education programs need to ensure students demonstrate the competencies required to manage increasingly complex and vulnerable patient populations prior to graduation.

Through high-fidelity patient simulation, students can practice nursing interventions, learn to prioritize care, improve communication skills, and observe effects of different clinical decisions without fear of harming a live patient. ${ }^{[6]}$ Simulation also provides opportunities to experience rare events that undergraduate nursing students may not experience during clinical placements, such as septic shock, myocardial infarction, respiratory distress and cardiac arrest. Outcomes of well-designed high-fidelity clinical simulations in an undergraduate nursing program include improved self-confidence and critical thinking, diminished anxiety, increased knowledge retention, and development of psychomotor skills. ${ }^{[6]}$ Results of an integrative review of the literature on preparing nursing students through simulation to recognize and respond to the deteriorating patient suggested that confidence, clinical judgement, knowledge and competence, vital in the care of a deteriorating patient were enhanced, but concluded that learners did not necessarily feel prepared for practice in real clinical settings. ${ }^{[7]}$ Results support the need for high-quality research using improved measurement practices to produce generalizable evidence of effectiveness of simulation. ${ }^{[8]}$ As well, an examination of of strategies used to prepare learners to participate in deteriorating patient simulations is warranted as this may impact their success during the simulation and subsequent clinical practice.

\subsection{Presimulation preparation strategies}

As simulation becomes an increasingly popular teaching strategy, the effectiveness of various approaches for simulation design, implementation and evaluation are becoming more important. While methods for scenario development and debriefing are widely reported in the literature, less research has focused on the presimulation phase, ${ }^{[9,10]}$ and there is limited validity and reliability evidence for evaluating simulation-based learning outcomes in nursing education. ${ }^{[11]}$ The presimulation phase consists of two distinct components: (1) pre-simulation preparation; and (2) pre-simulation briefing or prebriefing. ${ }^{[9,12]}$ Pre-simulation preparation consists of materials, activities and resources provided to learners at unspecified times in advance of a simulated clinical experience and completed prior to presimulation briefing. ${ }^{[12,13]}$ Whereas prebriefing occurs immediately prior to the simulation and consists of orienting learners to the environment (simulation setting, equipment, mannequin and procedures) and the simulation (learning objectives, roles, scenario). ${ }^{[13]}$

An important goal of prebriefing is to create an engaging environment where learners feel safe. Strategies for establishing psychological safety during simulation include the facilitator conveying respect and collaborating with learners to set clear boundaries regarding confidentiality and expectations for the session. ${ }^{[14]}$ Prebriefing may include learner engagement activities such as reviewing knowledge or skills, or time to plan for the simulation. ${ }^{[15]}$ Time may also be devoted to reviewing presimulation preparation activities and planning for the experience. This may take the form of a question and answer session, a review of a simulated patient chart, a group huddle, use of a prebriefing worksheet, facilitated reflection or concept mapping activities. ${ }^{[16,17]}$

The goal of presimulation preparation is to provide learners with the clinical content (knowledge and skills) to participate successfully in the simulated clinical experience. ${ }^{[18]}$ Traditionally, lectures, textbook readings, journal articles or clinical practice guidelines were assigned to learners for pre-simulation activities to be completed prior to particpatig in the simulation. ${ }^{[10,19,20]}$ Several studies have mentioned providing students with alternate presimulation preparation activities, such as concept mapping, group discussion, expert modelling videos, and/or voiceover PowerPoint lectures but few studies have compared traditional pre-scenario activities to alternate ones. ${ }^{[19-23]}$

Those studies that have compared traditional and alternative pre-simulation preparation methods demonstrated increased knowledge scores $^{[21]}$ and greater skill performance ${ }^{[20,22,23]}$ from alternative methods. The literature also suggests preparation can be guided by learning outcomes and descriptors 
provided by assessment rubrics, which may help learners recognize their knowledge gaps in advance and help them to achieve the learning outcomes. ${ }^{[24]}$ When simulation assessment rubrics are provided to learners as part of pre-simulation preparation, learners are made aware of outcomes and the criteria upon which their performance will be assessed. ${ }^{[25]}$

\subsection{Assessment of simulation learning outcomes}

Many nursing education programs struggle with how to evaluate simulation-based learning outcomes due to the lack of reliable and validated tools and metrics. ${ }^{[11]}$ Depending on the purpose and nature of the evaluation, observation-based simulation evaluation instruments used for assessing learning outcomes are checklists, rating-scales and rubrics. ${ }^{[11]}$ Checklists and rating-scales can be used to evaluate performance on technical and psychomotor skills during simulation; ${ }^{[11]}$ however, when assessing complex competencies, such as teamwork and leadership, it appears that rubrics are better suited. ${ }^{[26]}$ Generic rubrics help students to understand the key elements that must be addressed in a deteriorating patient scenario regardless of the particular situation which helps to further develop their skills and abilities. ${ }^{[27]}$ Some valid and reliable generic simulation rubrics have been developed to assess specific learning outcomes such as the Lasater Clinical Judgment Rubric which assesses clinical judgment during clinical simulation; ${ }^{[28]}$ however, rubrics that align directly with scenario-specific learning outcomes may provide an alternative option that support both presimulation preparation and debriefing for the learner and the simulation facilitator. Explicit learning objectives in rubrics also create consistency between assessments of student performance in similar activities and provide quality feedback to students, which ultimately contribute to learning.

\subsection{Theoretical framework}

A fundamental theory that informed the development of the new presimulation preparation and assessment process is Constructive Alignment, ${ }^{[29]}$ in which teaching and assessment are aligned to meet the learning outcomes. A generic "deteriorating patient" assessment rubric with learning outcomes was developed prior to the new simulation scenario development. Using "backward design" as described by Wiggins and McTighe, ${ }^{[30]}$ we created a deteriorating patient scenario that used previously developed learning outcomes and rubric descriptors as a scaffold. The literature suggests that learners are more likely to achieve learning outcomes when the teaching method provides them with a clear purpose and explicit performance goals. ${ }^{[30]}$ This aligns well with the theory of Self-Regulated learning (SRL) which involves three phases: (1) forethought (task analysis and self-motivation); (2) performance (self-control and self-observation); and (3) self-reflection (self-judgment and self-reaction). ${ }^{[31]}$ These phases align with the three phases of simulation: (1) presimulation/preparation; (2) participation; and (3) debriefing. ${ }^{[32]}$ Thus we propose that use of a learning outcomes assessment rubric will be a feasible method to support self-regulation and self-reflection during the presimulation preparation phase as learners are provided with the performance goals to guide their preparatory activities. As well the rubrics will support self-reflection by learners, and assessment by facilitators during the performance and debriefing phases.

\subsection{Project objectives}

Our project proposed to develop, implement and evaluate a non-traditional method to deliver clinical simulations to senior nursing students using a learning outcomes assessment rubric to guide presimulation preparation by learners and debriefing by facilitators. We aimed to demonstrate the feasibility of this method and determine learner satisfaction and perceived impact on learning.

\section{Project description}

Our report describes learner's self-assessed competence with management of deteriorating patients, and satisfaction with deteriorating patient simulations delivered using a traditional format (preparatory lecture/assigned readings) to a scenario delivered using a new format that incorporates an assessment rubric during presimulation preparation and debriefing.

\subsection{Participants}

A deteriorating patient scenario and learning outcomes assesment rubric related to care of a patient with respiratory distress were developed, implemented and evaluated in a fourth year undergraduate nursing students at one university within an existing critical care nursing course. Learners had previous experience with simulation in their second and third years of the program. Ethical approval was obtained from the Queen's University Health Sciences and Affiliated Teaching Hospitals Research Ethics Board (HSREB) to evaluate outcomes of this project.

\subsection{Intervention design and implementation}

Using the standardized scenario design process developed by the Ontario Simulation Alliance (OSA), ${ }^{[33]}$ a deteriorating patient scenario and scenario-specific learning outcome assessment rubric were developed. The scenario focused on a post-operative patient with a diagnosed deep vein thrombosis and a history of myocardial infarction who is now experiencing shortness of breath and chest pain. As the scenario progresses the patient is diagnosed with a pulmonary embolus and the patient's condition worsens to respiratory failure. 
Learning outcomes included in the learning outcomes assessment rubric focused on assessment, interventions, communication, collaboration and patient safety. Scenario and rubric content was validated by clinical and educational experts from collaborating institutions across the province. Facilitators are generally trained by the simulation lab manager or another faculty member who is a simulation expert. For the purposes of this study, facilitators were additionally trained by the lead researcher on the use of the assessment rubric using two standardized video-taped simulations. The scenario was trialed with the facilitators and then implemented at one Canadian university within an existing critical care nursing course. The researchers were not involved in facilitating any aspect of the simulations and did not teach the students in this course.

The students in this project participated in two unfolding clinical scenarios during the critical care nursing course. Participation in the simulations is mandatory, however, it is not graded, and is used only as a learning experience, with formative feedback provided to the group. All students completed the first scenario using the traditional simulation delivery format, and the second scenario using the non-traditional format. The first scenario, which focused on a deteriorating patient with a myocardial infarction, was delivered in the traditional manner with a preparatory lecture, an in situ pre- brief, participation in the scenario, followed by a debrief. The second scenario, the newly developed respiratory distress scenario, was delivered using the new format which consisted of pre-simulation preparation and assessment using a rubric, pre-brief, participation in the scenario, followed by a debrief and post-scenario assessment using a rubric (see Table 1). Learners were asked to complete a pre-assessment rubric prior to attending the simulation by rating their perceived ability to successfully meet the intended learning outcomes during the upcoming scenario. Learners are also expected to provide a rationale for each of their ratings to promote further self-reflection and accuracy of self-assessment. Following a standard prebrief that included the critical components of orientation and establishment of psychological safety, learners participated in the clinical simulation in groups of 8-10 students. Half of the students in each group participated during the first half of the scenario, while the remaining students observed using the rubric as a focus. At the midpoint of the unfolding scenario, the first group gave a handoff report to the observers who assumed care of the patient for the remainder of the scenario. The facilitator used the assessment rubric to assess each group and provide feedback to learners during debriefing which followed the GATHER, ANALYZE, SUMMARIZE (GAS) Model of Debriefing. ${ }^{[34]}$ Learner selfassessments and peer assessments were also incorporated into the debriefing on a volunteer basis.

Table 1. Components of traditional and non-traditional simulation delivery

\begin{tabular}{lll}
\hline Scenario & Simulation Format & Components \\
\hline \multirow{3}{*}{$\begin{array}{l}\text { Myocardial } \\
\text { Infarction }\end{array}$} & Traditional & 1. Preparation (lecture, readings, scenario learning outcomes) \\
& & 2. Prebrief (orientation, psychological safety) \\
& & 3. Participation in scenario \\
& 4. Debrief using GAS model of debriefing \\
& Non-Traditional: & 1. Preparation (lecture, readings, learning outcomes assessment rubric) \\
Respiratory Distress & 2. Pre-assessment with rubric (including rationale for ratings) \\
& Self-regulated learning & 3. Prebrief (orientation, psychological safety) \\
& using assessment rubric & 5. Porticipation in scenario \\
& & 6. Debrief with rubric using GAS model of debriefing \\
\hline
\end{tabular}

Note. GAS = Gather, Analyze, Summarize.

\subsection{Data collection and analysis}

A descriptive survey with quantitative and qualitative components was administered following learner participation in both simulation scenarios to evaluate satisfaction with the two simulation delivery formats. Perceived competence with management of deteriorating patients was measured through learner self-assessment using the rubric (see Figure 1) collected pre and post simulation and compared using paired samples $t$-tests. Each competency on the rubric was rated on a 3-point scale: 1 point (needs major improvement), 2 points (needs some improvement), or 3 points (meets competency).

\section{Results}

\subsection{Quantitative data}

Eighty-six senior nursing students completed both clinical scenarios and 83 provided pre and post rubric assessment data for the respiratory distress scenario and completed the satisfaction survey. Overall, self-assessed competence related to the deteriorating patient learning outcomes increased significantly following participation in the scenarios $(p<$

ISSN 1925-4040 E-ISSN 1925-4059 
.001) (see Figure 2). Learners were significantly more satis- agreed that having the learning objectives/assessment rubric fied with the respiratory distress scenario delivered using the new format which included the assessment rubric than with prior to the simulation helped them to prepare $(90 \%)$ and the cardiac scenario delivered using the standard format without the assessment rubric $(p<.001)$. The majority of learners

that assessing their competency with the rubric both prior to $(82.5 \%)$ and following the simulation (85\%) was helpful to their learning.

\begin{tabular}{|c|c|c|c|}
\hline \multicolumn{4}{|c|}{ LEARNING OUTCOME ASSESSMENT RUBRIC } \\
\hline $\begin{array}{l}\text { Competency/ } \\
\text { Learning Outcome }\end{array}$ & $\begin{array}{l}\text { Demonstrated attributes meet } \\
\text { competency requirements }\end{array}$ & $\begin{array}{l}\text { Demonstrated attributes need some } \\
\text { improvement to align with competency }\end{array}$ & $\begin{array}{l}\text { Demonstrated attributes need major } \\
\text { improvement to align with competency }\end{array}$ \\
\hline $\begin{array}{l}\text { Collaborate with team } \\
\text { members to deliver efficient } \\
\text { and effective nursing care }\end{array}$ & $\begin{array}{l}\text {-Relevant tasks are assigned to } \\
\text { appropriate team members } \\
\text {-Relevant tasks are completed in a } \\
\text { timely manner } \\
\text {-Knowledge and skill are shared with } \\
\text { team members as required } \\
\text {-Assistance is requested from team } \\
\text { members as required }\end{array}$ & $\begin{array}{l}\text {-Some relevant tasks are assigned to } \\
\text { appropriate team members } \\
\text {-Some relevant tasks are completed in a } \\
\text { timely manner } \\
\text {-Knowledge and skill sometimes shared } \\
\text { with team members } \\
\text {-Assistance is sometimes requested } \\
\text { from team members }\end{array}$ & $\begin{array}{l}\text {-Relevant tasks are not assigned to } \\
\text { appropriate team members } \\
\text {-Relevant tasks are not completed in a timely } \\
\text { manner } \\
\text {-Knowledge and skill are not shared with other } \\
\text { team members } \\
\text {-Assistance is never requested from team } \\
\text { members }\end{array}$ \\
\hline \multicolumn{4}{|l|}{ Comments/Rationale } \\
\hline $\begin{array}{l}\text { Communicate a critical } \\
\text { change in health status to } \\
\text { secure the appropriate } \\
\text { collaboration to treat the } \\
\text { patient's condition }\end{array}$ & $\begin{array}{l}\text {-Delivered data accurately portrays } \\
\text { critical nature of patient's condition } \\
\text { - Report is effective \& results in } \\
\text { immediate buy-in } \\
\text {-Secured collaboration is appropriate } \\
\text { for the needs of the patient }\end{array}$ & $\begin{array}{l}\text {-Delivered data somewhat accurately } \\
\text { portrays the critical nature of the } \\
\text { patient's condition } \\
\text {-Report is somewhat effective \& results } \\
\text { in some buy-in } \\
\text {-Secured collaboration is somewhat } \\
\text { appropriate for the needs of the patient }\end{array}$ & $\begin{array}{l}\text {-Delivered data does not accurately portray } \\
\text { the critical nature of the patient's condition } \\
\text {-Report is not effective \& results in little-to-no } \\
\text { buy-in } \\
\text {-Secured collaboration is inappropriate for the } \\
\text { needs of the patient }\end{array}$ \\
\hline \multicolumn{4}{|l|}{ Comments/Rationale } \\
\hline $\begin{array}{l}\text { Perform critical measures for } \\
\text { a patient } \\
\text { experiencing a decline } \\
\text { in health status to prevent } \\
\text { further deterioration of the } \\
\text { patient's condition until help } \\
\text { arrives }\end{array}$ & $\begin{array}{l}\text {-Actions reflect a thorough } \\
\text { understanding of significance of the } \\
\text { abnormal findings } \\
\text {-Implements appropriate } \\
\text { emergency measures } \\
\text {-Accesses resources that result in } \\
\text { effective management } \\
\text {-Demonstrates regard for the } \\
\text { urgency of the situation }\end{array}$ & $\begin{array}{l}\text {-Actions reflect some understanding of } \\
\text { significance of abnormal findings } \\
\text {-Implements some appropriate } \\
\text { emergency measures } \\
\text {-Accesses resources that result } \\
\text { in some effective management } \\
\text {-Demonstrates some regard for } \\
\text { the urgency of the situation }\end{array}$ & $\begin{array}{l}\text {-Actions reflect little to no } \\
\text { understanding of significance of the abnormal } \\
\text { findings } \\
\text {-Implements inappropriate } \\
\text { emergency measures } \\
\text {-Accesses resources that do } \\
\text { result in effective management } \\
\text {-Demonstrates little to no regard } \\
\text { for the urgency of the situation }\end{array}$ \\
\hline \multicolumn{4}{|l|}{ Comments/Rationale } \\
\hline $\begin{array}{l}\text { Identify threats to patient } \\
\text { safety to minimize the extent } \\
\text { of injury to a patient } \\
\text { experiencing a decline in } \\
\text { health status }\end{array}$ & $\begin{array}{l}\text {-Effectively carries out safety checks } \\
\text { - Care demonstrates a regard } \\
\text { for infection control practices } \\
\text {-Demonstrates accountability } \\
\text { for minimizing harm }\end{array}$ & $\begin{array}{l}\text {-Carries out some safety checks } \\
\text { - Care demonstrates some regard for } \\
\text { infection control practices } \\
\text {-Demonstrates some accountability for } \\
\text { minimizing harm }\end{array}$ & $\begin{array}{l}\text {-Fails to carry out safety checks } \\
\text { - Care demonstrates little to no regard for } \\
\text { infection control practices } \\
\text {-Demonstrates little to no accountability for } \\
\text { minimizing harm }\end{array}$ \\
\hline \multicolumn{4}{|l|}{ Comments/Rationale } \\
\hline $\begin{array}{l}\text { Communicate using } \\
\text { therapeutic principles } \\
\text { to decrease anxiety in } \\
\text { the patient during an } \\
\text { emergency situation }\end{array}$ & $\begin{array}{l}\text {-Uses a caring demeanour, resulting in } \\
\text { compliance with care } \\
\text {-Interacts with patient in a way that } \\
\text { facilitates open communication } \\
\text {-Demonstrates a regard for respecting } \\
\text { patient \& family's right to be informed } \\
\text {-Conveys information to patient \& } \\
\text { family in a way that promotes } \\
\text { understanding }\end{array}$ & $\begin{array}{l}\text {-Uses a somewhat caring demeanour, } \\
\text { resulting in some compliance with care } \\
\text {-Interacts with patient in a way that } \\
\text { facilitates some open communication } \\
\text {-Demonstrates some regard for } \\
\text { respecting patient \& family's right to be } \\
\text { informed } \\
\text {-Conveys information to patient \& } \\
\text { family in a way that promotes some } \\
\text { understanding }\end{array}$ & $\begin{array}{l}\text {-Does not use a caring demeanour, resulting in } \\
\text { little to no compliance } \\
\text {-Interacts with the patient in a way that does } \\
\text { not facilitate open communication } \\
\text {-Demonstrates little to no regard } \\
\text { for respecting patient \& family's right to be } \\
\text { informed } \\
\text {-Conveys information to patient \& family in a } \\
\text { way that does not promote understanding }\end{array}$ \\
\hline \multicolumn{4}{|l|}{ Comments/Rationale } \\
\hline $\begin{array}{l}\text { Use effective documentation } \\
\text { tools to } \\
\text { ensure the events of the } \\
\text { emergency are appropriately } \\
\text { recorded }\end{array}$ & $\begin{array}{l}\text {-Records details of event in a } \\
\text { timely manner } \\
\text {-Data is documented so as to } \\
\text { accurately represent the sequence of } \\
\text { the ensuing events } \\
\text {-Documentation follows institutional } \\
\text { policy }\end{array}$ & $\begin{array}{l}\text {-Records details of event in a somewhat } \\
\text { timely manner } \\
\text {-Data is documented so as to somewhat } \\
\text { accurately represent the sequence of } \\
\text { the } \\
\text { ensuing events, however some } \\
\text { clarification is needed } \\
\text {-Documentation somewhat follows } \\
\text { institutional policy }\end{array}$ & $\begin{array}{l}\text {-Does not record details of event in a timely } \\
\text { manner } \\
\text {-Data is not documented so as to accurately } \\
\text { represent the sequence of the ensuing events } \\
\text { \& requires extensive } \\
\text { clarification } \\
\text {-Documentation does not follow institutional } \\
\text { policy }\end{array}$ \\
\hline Comments & & & \\
\hline
\end{tabular}

Figure 1. Learning outcomes assessment rubric

Published by Sciedu Press 


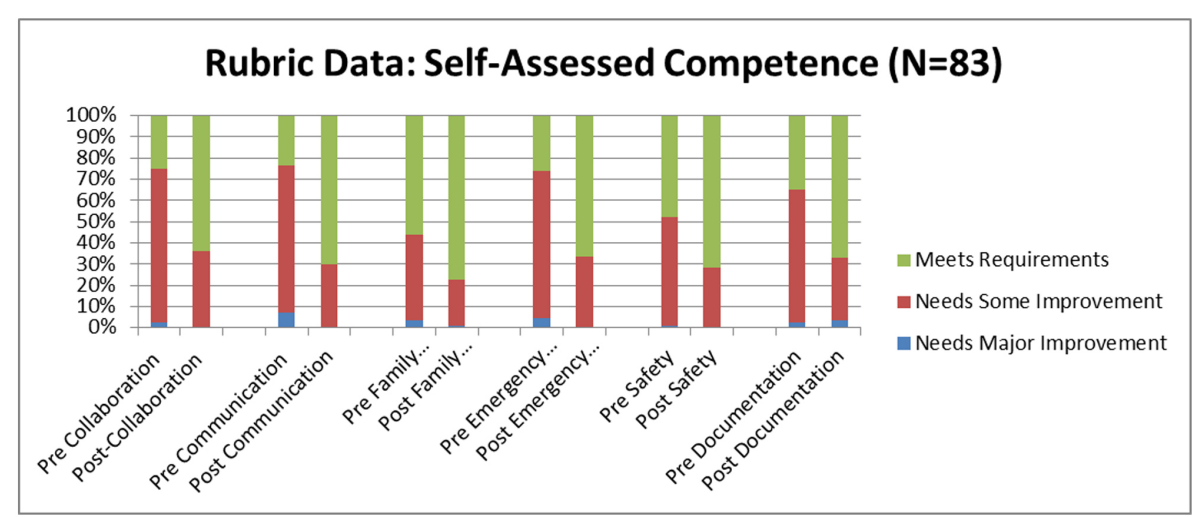

Figure 2. Learner self-assessed competence with managing a deteriorating patient

\subsection{Qualitative data}

Qualitative survey feedback also highlighted the value of the rubrics in helping students to identify their own strengths and learning needs (see Table 2). Suggested improvements included using the new simulation format for other simulations. Some learners found self-assessment with the rubrics to be challenging.

Table 2. Learner feedback about simulation delivery using self-assessment rubrics

\begin{tabular}{|c|c|}
\hline Helpful Aspects & Suggestions for Improvement \\
\hline $\begin{array}{l}\text {-knowing the case study, being able to prepare beforehand } \\
\text {-having the rubric to look for what objectives needed to be met } \\
\text {-expectations were clearly outlined } \\
\text { - the list of competencies so that I was able to review those that I } \\
\text { felt were not my strengths } \\
\text {-I was able to understand what I needed to know before the lab } \\
\text { and focus on skills and team collaboration during the sim itself } \\
\text {-made me look over my notes on the topic before the sim lab } \\
\text {-I liked the prep package for the respiratory lab } \\
\text {-getting learning outcomes and rubric ahead of time helped me } \\
\text { look at what was being assessed and what was expected to learn }\end{array}$ & $\begin{array}{l}\text {-include the patient information for both labs } \\
\text {-continue to give this information prior to the lab } \\
\text {-give the learner package ahead of time for the cardiac lab as } \\
\text { well, the prep work was very effective in preparing for the } \\
\text { respiratory lab } \\
\text {-I didn't find the rubric particularly helpful, it was having the } \\
\text { patient information beforehand so I could research that was } \\
\text { helpful } \\
\text {-have an example demonstration video of how to best approach } \\
\text { these situations so that we can prepare } \\
\text {-the self-assessments were hard to do-it's hard assessing } \\
\text { yourself } \\
\text {-some students in the group had a better idea of the prep content } \\
\text { than others }\end{array}$ \\
\hline
\end{tabular}

\section{Discussion}

Assessment rubrics have been often been used in education to provide a standardised marking scheme, as well as to provide feedback to learners. ${ }^{[35]}$ Results of a review in higher education determined that assessment rubrics enhanced learner self-assessment, self-regulation and understanding of assessment criteria. ${ }^{[36]}$ Self-regulated learning (SRL) is a core conceptual framework that describes the cognitive, motivational and emotional aspects of learning. ${ }^{[37]}$ Each phase corresponds to a phase of a simulation-based learning experience: forethought with presimulation preparation; performance with participation in a simulation; and self-reflection with debriefing. Thus use of a learning outcomes assessment rubric was proposed to support self-regulated learning during a deteriorating patient simulation experience. This is consis- tent with the quantitative and qualitative feedback provided by our participants who valued the use of the rubric in both the presimulation preparation and debriefing phases of the simulation and requested the new format be used for other simulations. Some learners found it difficult to complete self-assessments using the rubrics. This indicates a need for more explicit instructions and practice using the rubrics. It is anticipated that with repeated exposures learners' selfassessment ability would improve, and learners would begin to see their performance errors as an essential component of learning and developing competence. ${ }^{[38]}$ Instructor feedback and comparisons with self-assessed ratings would also enhance learner self-assessments, a critical component of self-regulated learning. 
Learner preference for this alternate method of presimulation preparation also aligns with results of a systematic review that indicated nontraditional presimulation preparation methods were highly rated. ${ }^{[19]}$ The review also reported higher levels of learning associated with alternate preparation. Further evaluation of the use of learning outcomes assessment rubrics to prepare and to debrief students participating in simulations should include objective measures of knowledge. Trained assessors could use the rubrics to evaluate performance in groups of students prepared with and without the rubrics. Through self-assessment with the rubrics, our learners reported they perceived their competence in managing a deteriorating patient experiencing respiratory distress improved following participation in the scenario. This agrees with results of a recent systematic review and meta-analysis that indicated nursing student knowledge, performance and self-confidence with recogntion and response to deteriorating patients improves with high-fidelity simulation. ${ }^{[8]}$ Thus our initial implementation suggests the integration of learning outcomes assessment rubrics into simulation can support presimulation preparation and self-regulated learning, as well as formative assessment of achievement of intended learning outcomes. Further study is needed to validate the use of the rubrics for summative or high-stakes assessment purposes, and to determine the learning outcomes impacted by self-regulated simulation preparation.

\section{Limitations}

This pilot implementation of a new simulation scenario and learning outcomes assessment rubric was conducted halfway into the fall academic session, precluding testing in a randomized controlled study design; however, all learners were able to experience simulation delivery with and without the learning outcomes assessment rubric, and were thus able to comment on both formats. Providing more learning activities is usually associated with greater learner satisfaction; however, through qualitative feedback learners were able to articulate the aspects of the presimulation preparation that were helpful to their learning. Self-assessment of competence is another limitation, as it is known that overconfidence may inflate accurate self-assessment while high performers tend to underestimate their ability ${ }^{[39]}$ however, learners in our program and in this study are expected to provide a rationale for their self-ratings which may enhance their accuracy. As learners participated in groups of 8-10 students, it was not possible for the instructor to provide individualized feedback to each student; however the facilitator was able to use the assessment rubric to guide the debriefing and encourage learner self-reflection. As this project was conducted with senior nursing students, it is not clear whether novice nursing students would perceive the same benefits from this method of simulation delivery.

\section{Conclusion}

This project demonstrated that it is feasible to implement a learning outcomes assessment rubric as part of presimulation preparation in a critical care nursing course for senior nursing students, and that learners preferred this method to traditional presimulation preparation with lecture and assigned readings. Senior nursing students perceived that integration of learning outcomes assessment rubrics into simulation design enhanced their self-regulated learning and presimulation preparation. Learner satisfaction with the new deteriorating patient scenario and the accompanying assessment rubric was very high, and learners reported increased competence related to the learning outcomes. Learners valued the opportunity to identify their own learning needs related to the competencies required by the respiratory distress scenario, and suggested that the cardiac scenario be delivered in the same manner in the future. Thus the cardiac scenario was modified to fit the OSA scenario template and an assessment rubric was developed based on the learning outcomes for the scenario.

Further research to establish the reliability and validity of the learning outcomes assessment rubrics is underway which will determine their suitability for summative or high-stakes assessment. Additional clinical simulation scenarios and assessment rubrics developed using the OSA simulation design process will be implemented within the curriculum using the new simulation delivery format. The overall goal of this innovative project is to contribute to improved patient safety by enhancing self-regulated learning and critical thinking skills, and better prepare nursing students to transition to their professional practice roles. Further high-quality research is recommended to demonstrate these outcomes using a variety of innovative presimulation preparation, facilitation and debriefing methods.

\section{Conflicts of InTerest Disclosure}

The authors declare that there is no conflict of interest.

\section{REFERENCES}

[1] Massey D, Chaboyer W, Aitken L. Nurses' perceptions of accessing a medical emergency team: A qualitative study. Australian Critical
Care. 2014 Aug; 27(3): 133-138. https ://doi.org/10.1016/j. aucc.2013.11.001

[2] Purling A, King L. A literature review: Graduate nurses' prepared- 
ness for recognizing and responding to the deteriorating patient. Journal of Clinical Nursing. 2012; 21: 3451-3465. PMid:23145516 https://doi.org/10.1111/j.1365-2702.2012.04348.x

[3] Ratta C. Challenging graduate nurses' transition: Care of the deteriorating patient. Journal of Clinical Nursing. 2016 Oct; 25: 3036-3048. https://doi.org/10.1111/jocn. 13358

[4] Bogossian F, Cooper S, Cant R, et al. Undergraduate nursing students' performance in recognizing and responding to sudden patient deterioration in high psychological fidelity simulated environments: An Australian multi-centre study. Nurse Education Today. 2014 May; 34(5): 691-696. https://doi.org/10.1016/j.nedt.2013.09.015

[5] Levett-Jones T, Hoffman K, Dempsey J, et al. The 'five rights' of clinical reasoning: An educational model to enhance nursing students' ability to identify and manage clinically 'at risk' patients. Nurse Education Today. 2010 Aug; 30(6): 515-520. https : //doi.org/10.1016/j.nedt.2009.10.020

[6] Stroup C. Simulation usage in nursing fundamentals: Integrative literature review. Clinical Simulation in Nursing. 2014 Mar; 10(3): 155-164. https://doi .org/10.1016/j . ecns . 2013.10.004

[7] Fisher D, King L. An integrative review on preparing nursing students through simulation to recognize and respond to the deteriorating patient. Journal of Advanced Nursing. 2013 Nov; 69(11): 2375-2388 https://doi.org/10.1111/jan.12174

[8] Haddeland K, Slettebo A, Carstens P. Nursing students managing deteriorating patients: A systematic review and meta-analysis. Clinical Simulation in Nursing. 2018; 21: 1-15. https://doi.org/10.1 016/j.ecns. 2018.05.001

[9] Tyerman J, Luctkar-Flude M, Graham L, et al. Pre-simulation preparation and briefing practices for healthcare professionals and students: A systematic review protocol. JBI Database of Systematic Reviews and Implementation Reports. 2016; 14(8): 80-89. PMid:27635748 https://doi.org/10.11124/JBISRIR-2016-003055

[10] Leigh G, Steuben F. Setting learners up for success: Presimulation and prebriefing strategies. Teaching and Learning in Nursing. 2018 July; 13(3): 185-189. https://doi.org/10.1016/j.teln. 201 8.03 .004

[11] Kardong-Edgren S, Adamson K, Fitzgerald C. A review of currently published evaluation instruments for human patient simulation. Clinical Simulation in Nursing. 2010; 6(1): e25-e35. https: //doi.org/10.1016/j.ecns.2009.08.004

[12] Oermann M, Shellenbarger T, Gaberson K. Clinical teaching strategies in nursing. 5th ed. New York: Springer Publishing Company; 2018.

[13] INACSL Standards Committee. INACSL standards of best practice: SimulationSM: Simulation design. Clinical Simulation in Nursing. 2016; 12(S): S5-S12. https://doi.org/10.1016/j.ecns . 201 6.09 .005

[14] Rudolph J, Raemer D, Simon R. Establishing a safe container for learning in simulation. Simulation in Healthcare: Journal of the Society for Simulation in Healthcare. 2014 Dec; 9(6): 339-349. https://doi.org/10.1097/SIH.0000000000000047

[15] Chamberlain J. Prebriefing in nursing simulation: A concept analysis using Rodger's methodology. Clinical Simulation in Nursing. 2015 July; 11(7): 318-322. https://doi .org/10.1016/j . ecns . 201 5.05 .003

[16] McDermott D. The prebriefing concept: A Delphi study of CHSE experts. Clinical Simulation in Nursing. 2016 June; 12(6): 219-227. https://doi.org/10.1016/j.ecns.2016.02.001

[17] Page-Cutrara K, Turk M. Impact of prebriefing on competency performance, clinical judgment and experience in simulation: An experimental study. Nurse Education Today. 2017; 48: 78-83.
PMid:27721089 https://doi.org/10.1016/j.nedt.2016.09 .012

[18] Tyerman J, Luctkar-Flude M, Graham L, et al. A systematic review of health care presimulation preparation and briefing effectiveness. Clinical Simulation in Nursing. 2019; 27: 12-25. https : //doi.org/10.1016/j.ecns. 2018.11.002

[19] Birch L, Jones N, Doyle P, et al. Obstetric skills drills: Evaluation of teaching methods. Nurse Education Today. 2007 Nov; 27(8): 915922. https://doi.org/10.1016/j.nedt.2007.01.006

[20] Bowyer M, Hanson J, Pimentel E. Teaching breaking bad news using mixed reality simulation. Journal of Surgical Research. 2010 Mar; 159(1): 462-467. https://doi.org/10.1016/j.jss.2009.04. 032

[21] Davis Bye B. Interactive pre-simulation strategies: Engaging students in experiential learning from the start. Journal of Systemics, Cybernetics and Informatics. 2014; 12(1): 69-75.

[22] Franklin A, Sideras S, Gubrud-Howe P, et al. Comparison of expert modeling versus voice-over PowerPoint lecture and presimulation readings on novice nurses' competence of providing care to multiple patients. Journal of Nursing Education. 2014; 53: 615-622. PMid:25350900 https://doi.org/10.3928/01484834-20141 023-01

[23] Pucher P, Aggarwal R, Singh P, et al. Ward simulation to improve surgical ward round performance. Annals of Surgery. 2014 Aug; 260(2): 236-243. https://doi.org/10.1097/SLA. 0000000000000557

[24] Ellery K. Assessment for learning: A case study using feedback effectively in an essay-style test. Assessment \& Evaluation in Higher Education. 2008 Aug; 33(4): 421-429. https : //doi .org/10.108 0/02602930701562981

[25] Higgins R, Hartley P, Skelton A. The conscientious consumer: Reconsidering the role of assessment feedback in student learning. Studies in Higher Education. 2002; 27(1): 53-64. https : //doi .org/10.1 080/03075070120099368

[26] Jonsson A, Svingby G. The use of scoring rubrics: Reliability, validity and educational consequences. Educational Research Review. 2007 Dec; 2: 130-144. https://doi .org/10.1016/j . edurev. 2 007.05 .002

[27] Learn Alberta. Generic rubrics. [Internet]. 2007. Available from: http://www.learnalberta.ca/content/mewa/html/ assessment/genericrubrics.html

[28] Adamson K, Gubrud P, Sideras S, et al. Assessing the reliability, validity, and use of the Lasater Clinical Judgment Rubric: Three approaches. Journal of Nursing Education. $2012 \mathrm{Feb}$; 51(2): 66-73. https://doi.org/10.3928/01484834-20111130-03

[29] Biggs J. Teaching for quality learning at university. Buckingham: Society for Research into Higher Education and Open University Press; 1999.

[30] Wiggins GP, McTighe J. Understanding by design. Alexandria, VA: Association for Supervision and Curriculum Development; 2008.

[31] Zimmerman B, Moylan A. Self-regulation: Where metacognition and motivation intersect. In D Hacker, J Dunlosky \& A Graesser (Eds.), Handbook of Metacognition in Education (pp. 299-315). New York: Routledge; 2009.

[32] Luctkar-Flude M. Simulation approaches. In P. Bradley \& K. PageCutrara (Eds.). Becoming a Nurse Educator in Canada. Ottawa: Canadian Association of Schools of Nursing (CASN); 2019 (in press).

[33] Luctkar-Flude M, Egan R, Tregunno D, et al. The OSA Simulation Design Process: Application of a standardized approach to the measurement of simulation outcomes to a communication simulation. Toronto: Ontario Simulation Exposition; 2014.

[34] Cheng A, Rodgers D, van der Jagt E, et al. Evolution of the Pediatric Advanced Life Support course: Enhanced learning with a new debrief- 
ing tool and web-based module for Pediatric Advanced Life Support instructors. Pediatric Critical Care Medicine. 2012 Sep; 13(5): 589595. https://doi.org/10.1097/PCC.0b013e3182417709

[35] Brookhart S, Chen F. The quality and effectiveness of descriptive rubrics. Educational Review. 2015; 67(3): 343-368. https: //doi.org/10.1080/00131911.2014.929565

[36] Cockett A, Jackson C. The use of assessment rubrics to enhance feedback in higher education: An integrative literature review. Nurse Education Today. 2018 Oct; 69: 8-13. https://doi .org/10.101 $6 / j$.nedt.2018.06.022

[37] Panadero E. A review of self-regulated learning: Six models and four directions for research. Frontiers in Psychology. 2017; 8(422): 1-28. https://doi.org/10.3389/fpsyg.2017.00422

[38] Bjork R, Dunlosky J, Kornell N. Self-regulated learning: Beliefs, techniques and illusions. Annual Review of Psychology. 2013 Jan; 64: 417-444. https://doi.org/10.1146/annurev-psych-1 13011-143823

[39] Sears K, Godfrey C, Luctkar-Flude M, et al. Measuring competence in healthcare learners and healthcare professionals by comparing self-assessment with objective structured clinical examinations: A systematic review. JBI Database of Systematic Reviews \& Implementation Reports. 2014; 12(11): 221-272. https://doi.org/10.111 24/jbisrir-2014-1605 